\title{
BEHAVIOUR OF SFRC FILLED STEEL TUBE COLUMNS UNDER AXIAL LOAD
}

\author{
Soner Guler *, Erol Lale and Metin Aydogan \\ Faculty of Civil Engineering, Istanbul Technical University, Istanbul, Turkey \\ *(Corresponding author: E-mail: gulersoner@hotmail.com)
}

Received: 29 August 2011; Revised: 26 September 2011; Accepted: 14 November 2011

\begin{abstract}
This paper presents an experimental study of square high strength steel fiber reinforced concrete (SFRC) filled steel tube columns under axial load. A series of tests are performed to investigate the effects of D/t ratio, the bond strength between concrete and the steel tube on behavior and axial load capacity of the high strength SFRC filled steel tube columns. The specimens are separated as greased and non-greased to investigate the bond effect on the axial load capacity. A total of 13 specimens are tested and compared to Eurocode 4, ACI, AS and AISC Codes. The results show that the difference of the axial load capacity between the greased and the non-greased square high strength SFRC filled tube columns is notable. The all design codes overestimate the axial load capacity for the specimens with thinner (D/t ratio is 33.3) steel tube thickness.
\end{abstract}

Keywords: Axial load capacity, Steel fiber reinforced concrete, Design codes, Bond effect, D/t ratio

\section{INTRODUCTION}

In high-rise buildings, the use of the high-strength concrete at structural members is quite widespread today. The structural members have to resist axial load and bending moment because of vertical and lateral loads. Therefore, the structural members such as columns have to be designed to sustain all kinds of effects which stem from those forces. The main aim of the concrete filled steel tube columns is to withstand against those forces by combining steel and concrete.

There have been many studies about the normal and the high strength concrete filled steel tube columns. Furlong [1] investigates 13 specimens with $\mathrm{D} / \mathrm{t}$ ratios from 29 to 98 . The results show that there is no increase in the load carrying capacity if the steel tube and the concrete resist the load individually. Schneider [2] performs a comprehensive study about axially loaded concrete filled steel tubes. The total 14 specimens are tested under the axial load, and experimental results are compared to numerical solutions. As conclusions states, the circular concrete filled steel tube columns show more ductility and strength compared to square and rectangular ones.

One of the most important parameters in this study is the bond effect. Due to the mechanical properties of the high strength concrete such as Poisson ratio and the amount of shrinkage differ from the low or medium strength concrete, the bond strength between the steel tube and the concrete core is critical on the axial load capacity for high strength concrete filled steel tube columns. There have been many studies to investigate the bond effect for the concrete filled tube columns by various researchers. Roeder et.al [3] studies the composite action in concrete filled tubes and emphasizes the importance of the bond stress between the concrete core and the steel tube. The results show that the bond capacity becomes smaller as the diameter and $\mathrm{D} / \mathrm{t}$ ratios of tubes increase. They develop a formulation that estimates the bond stress capacity. Giakoumelis and Lam [4] investigate 15 circular columns with 30,60 and $85 \mathrm{MPa}$ concrete strength, and $\mathrm{D} / \mathrm{t}$ ratio between 22.9 and 30.5. The specimens are separated as greased and non-greased specimens to investigate the bond effect. The results show that the difference of the axial load capacity of greased and non-greased specimens is very small for 30 and $50 \mathrm{MPa}$ concrete. The bonding of the steel and the concrete seem to be effective for $85 \mathrm{MPa}$ concrete while the percentage of difference between greased and non-greased specimens of axial load capacity is $14 \%$. The bond capacity between the steel tube and the concrete core is investigated by Morishita and Tomii [5], Virdi and Dowling [6]. 
With the development of concrete technology, there has been a remarkable advancement in developing higher performance concrete possessing high strength, toughness, energy absorption, fracture of energy, durability, etc. Steel fiber reinforced concrete (SFRC) may be defined as a composite material made with Portland cement, aggregate and incorporating discrete discontinuous fibers. 1. Swamy RN. High-strength concrete-material properties and structural behaviors. ACI SP-87, Detroit: American Concrete Institute; 1987. p. 110-146 Thus, a concrete mix possessing the higher axial ductility, bending or tensile strength as well as the high compressive strength can be obtained.

Although there have been many studies on CFT columns with low, normal and high strength concrete, there has been relatively little research on steel fiber reinforced concrete (SFRC) filled concrete filled tube columns.

Campiogne et al. [7] conduct a series of tests on the circular SFRC filled steel tube columns under axial load. The column lengths are $400 \mathrm{~mm}, 1500 \mathrm{~mm}$ and $2000 \mathrm{~mm}$. The steel fiber volume ratio is $1 \%$. They compare SFRC filled steel tube columns to plain concrete filled tube columns having compressive strength of $24 \mathrm{MPa}$. The aim of the study is to investigate the ductile post-peak behavior of these two types of concrete filled steel tube columns and to compare the axial load capacity of the test results with the design codes. The results show that the SFRC filled steel tube columns show more ductile behavior than the plain concrete filled steel tube columns. Tests of concrete-filled steel tube columns to investigate these effects are conducted by Uy [8]; Han [9]; $\mathrm{Hu}$ [10]; Young and Ellobody [11]; Teng et al. [12]; Zhong [13]; Liang [14]; Zhao et.al. [15] and many other researchers.

This paper reports an experimental study that is performed to analyze the behavior of square high strength SFRC filled steel tube columns under axial load. The first aim of this study is to report a series of new tests on square high strength SFRC filled steel tube columns under axial load. Second, the difference of the axial load capacity due to the bond effect is examined for high strength square SFRC filled steel tube columns depending on the different $\mathrm{D} / \mathrm{t}$ ratio of the specimens. Third, some important parameters such as ductility index (DI) and the strength enhancement index (SI) are investigated for the high strength SFRC filled steel tube columns. Fourth, the axial load capacity of the high strength SFRC filled steel tube columns are compared to the predicted ultimate strengths using the present design codes such as Eurocode 4, ACI and AS, AISC-LRFD 1999.

\section{EXPERIMENTAL PROGRAM}

A total of 13 square specimens are tested under axial load. The inside of the some steel tubes are greased to provide a weak interaction between the steel tube and the concrete core and to investigate the bond effect on the axial load capacity of high strength SFRC filled steel tube columns.

The wall thickness of the steel tubes is 3,4 and $5 \mathrm{~mm}$. The dimension of the square section is 100 $\mathrm{mm} \times 100 \mathrm{~mm}$. The $\mathrm{D} / \mathrm{t}$ ratio varies from 20 and 33.3. All specimens are $400 \mathrm{~mm}$ in length to prevent the slenderness effect and to ensure that the specimens behave as stub columns. The square column specimens before and after concrete is poured are shown in Figure 1. All the tests are performed at the Istanbul Technical University, Civil Engineering Department in Structural Laboratory. Testing of the high strength concrete filled steel tube columns are performed using a $5000 \mathrm{kN}$ capacity INSTRON testing machine. 

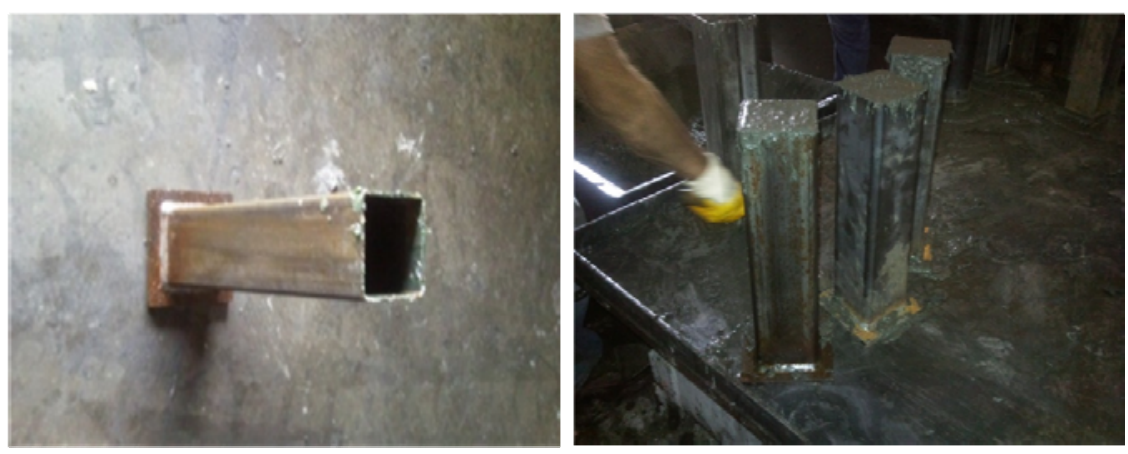

Figure 1. The Square Column Specimens before and after Concrete Filled

\subsection{Concrete Properties}

Steel fiber reinforced concrete (SFRC) is produced to enhance the mechanical properties of concrete such as the compressive strength and ductility. The high strength SFRC for the composite columns is mixed in one batch. Dramix ZP 305 steel fibers are used in the mix at two percent (2\%) by volume. The fibers in the mix have a diameter of $0.55 \mathrm{~mm}$, a length $30 \mathrm{~mm}$, tensile strength of $1100 \mathrm{MPa}$. The type of cement CEM I PÇ 42.5R is used as cement material in the mix. A super plasticizer is used for mix, the amount being varied to maintain approximately the same workability. The mixture proportions of the matrix are as follows; cement: silica fume: water: siliceous sand $(0.5-2 \mathrm{~mm})$ : siliceous powder $(0-0.5 \mathrm{~mm})$ : super plasticizer $=1: 0.250: 0.12: 0.325: 0.5: 0.13$. Water-binder ratio is kept constant at 0.13 . The typical mix composition of the high strength SFRC used in this study is shown in Table 1.

Table 1. Steel Fiber Reinforced Concrete Mix Design

\begin{tabular}{|l|l|}
\hline & $\begin{array}{l}\text { Mix proportions } \mathrm{kg} \\
\text { (for 1 m3 concrete) }\end{array}$ \\
\hline Cement & 1000 \\
\hline Siliceous sand $(0.5-2 \mathrm{~mm})$ & 325 \\
\hline Siliceous powder $(0-0.5 \mathrm{~mm})$ & 500 \\
\hline Silica fume & 250 \\
\hline Super plasticizer & 130 \\
\hline Water & 165 \\
\hline ZP 305 Dramix steel fiber & 160 \\
\hline Total & 2530 \\
\hline
\end{tabular}

The target concrete compressive cylinder strength $\left(f_{c y l, 150}\right)$ at 28 days approximately is $100 \mathrm{MPa}$. Standard cylinder $(150 \mathrm{~mm} \times 300 \mathrm{~mm})$ tests are carried out in accordance to Turkish Standard TS EN 206 to determine the compressive strength. The concrete cylinder specimens are tested at a loading rate of 300 and $250 \mathrm{kN} / \mathrm{min}$. Cylinders size are $150 \mathrm{~mm}$ diameter and $300 \mathrm{~mm}$ length. The average compressive strength $\left(f_{c k}\right)$ at the time of test is $115 \mathrm{MPa}$. Each layer of concrete is compacted using a poker vibrator. The modulus of elasticity of concrete is the tangent modulus at one-third the ultimate strength and measured in accordance with Turkish standards (TS EN 206-1). The average modulus of elasticity value is $42579 \mathrm{MPa}$. 


\section{$2.2 \quad$ Steel Properties}

The tubes are all manufactured from mild steel by the steel company. In order to determine the actual material properties, three coupons are cut from each steel tube having different steel tube according to Turkish Standard TS 138 EN 10002. The average yield stress, tensile strength, and modulus of elasticity are $304 \mathrm{MPa}, 400 \mathrm{MPa}$, and $200000 \mathrm{MPa}$, respectively.

Figure 2 shows the typical stress-strain relation for the each steel coupon measured in the tension tests according to Turkish standard TS 138 EN 10002.

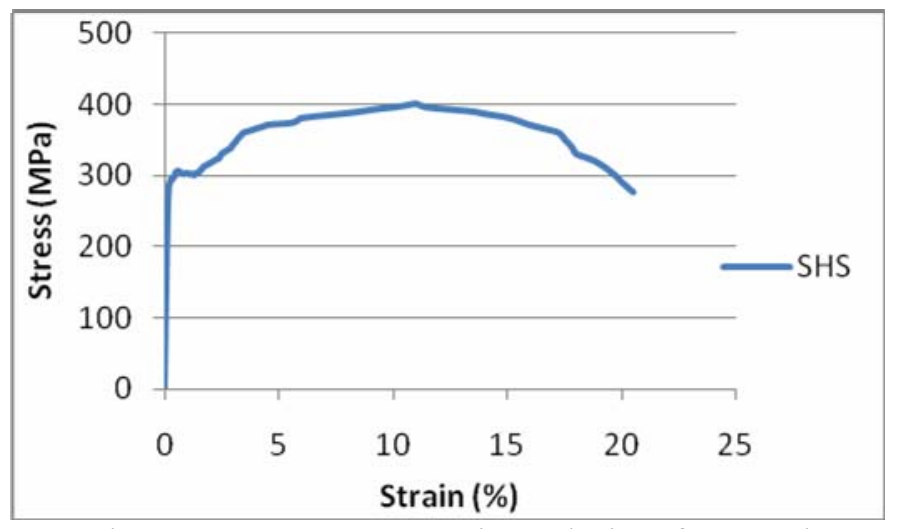

Figure 2. The Average Stress-strain Relation for Steel Coupons

\section{$2.3 \quad$ Test Set-up}

The specimens are loaded at $30 \mathrm{kN}$ intervals at the beginning of the test and at a loading rate of 10 $\mathrm{kN}$ intervals after the column begin to yield. All the tests are performed on a $5000 \mathrm{kN}$ capacity testing machine. Two linear variable differential transducers $\left(\mathrm{LVDT}_{\mathrm{s}}\right)$ are placed in diametrically opposite positions equally placed at each side of the column to measure the axial deformation. Four strain gauges are used for each specimen to measure strains at the middle height, two strain gauges at the top and two strain gauges at the bottom. The test setup is shown in Figure 3.

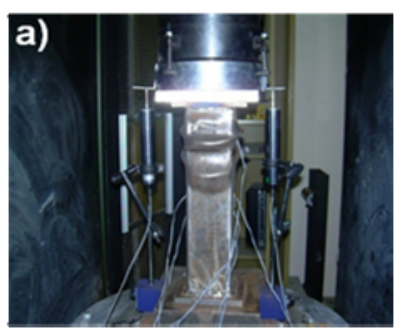

Figure 3. a) The Test Set Up

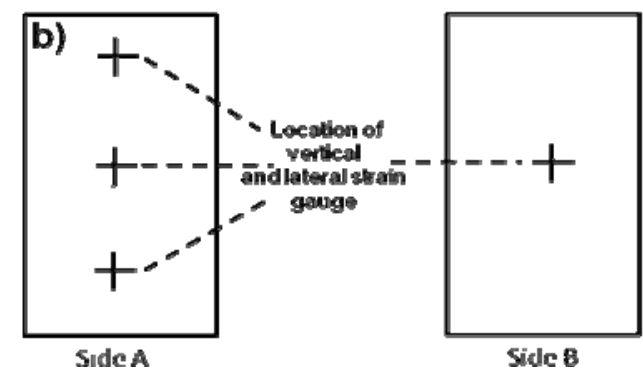

b) Location of Strain Gauges

The specimens are labeled according to their shape of the steel tube, greased or non-greased, the thickness of steel tube and the number of that group. For example, $\mathrm{S} 3 \mathrm{G}-1$, it is denoted ' $\mathrm{S}$ ' square, ' 3 ' the thickness of the steel tube, ' $G$ ' greased and ' 1 ' the number of that specimen. S5NG-2, it is denoted ' $S$ ' square, ' 5 ' the thickness of the steel tube, ' $N G$ ' non-greased, ' 2 ' the number of that specimen. The geometrical and material properties of the specimens are shown in the Table 2. 
Table 2. Geometric and Material Properties of Specimens

\begin{tabular}{|c|c|c|c|c|c|c|c|}
\hline No & $\begin{array}{c}\mathrm{D} \times \mathrm{B} \times \mathrm{t} \\
(\mathrm{mm})\end{array}$ & $\begin{array}{c}\mathrm{L} \\
(\mathrm{mm})\end{array}$ & $\mathrm{D} / \mathrm{t}$ & $\begin{array}{c}f_{c} \\
(\mathrm{Mpa})\end{array}$ & $\begin{array}{c}f_{y} \\
(\mathrm{Mpa})\end{array}$ & $\begin{array}{c}\mathrm{A}_{\mathrm{s}} \\
\left(\mathrm{mm}^{2}\right)\end{array}$ & $\begin{array}{c}\mathrm{A}_{\mathrm{c}} \\
\left(\mathrm{mm}^{2}\right)\end{array}$ \\
\hline S3G-1 & $100 \times 100 \times 3$ & 400 & 33,3 & 115 & 304 & 1164 & 8836 \\
\hline S3G-2 & $100 \times 100 \times 3$ & 400 & 33,3 & 115 & 304 & 1164 & 8836 \\
\hline S3G-3 & $100 \times 100 \times 3$ & 400 & 33,3 & 115 & 304 & 1164 & 8836 \\
\hline S3NG-1 & $100 \times 100 \times 3$ & 400 & 33,3 & 115 & 304 & 1164 & 8836 \\
\hline S3NG-2 & $100 \times 100 \times 3$ & 400 & 33,3 & 115 & 304 & 1164 & 8836 \\
\hline S4G-1 & $100 \times 100 \times 4$ & 400 & 25 & 115 & 304 & 1536 & 8464 \\
\hline S4G-2 & $100 \times 100 \times 4$ & 400 & 25 & 115 & 304 & 1536 & 8464 \\
\hline S4NG-1 & $100 \times 100 \times 4$ & 400 & 25 & 115 & 304 & 1536 & 8464 \\
\hline S4NG-2 & $100 \times 100 \times 4$ & 400 & 25 & 115 & 304 & 1536 & 8464 \\
\hline S5G-1 & $100 \times 100 \times 5$ & 400 & 20 & 115 & 304 & 1900 & 8100 \\
\hline S5G-2 & $100 \times 100 \times 5$ & 400 & 20 & 115 & 304 & 1900 & 8100 \\
\hline S5NG-1 & $100 \times 100 \times 5$ & 400 & 20 & 115 & 304 & 1900 & 8100 \\
\hline S5NG-2 & $100 \times 100 \times 5$ & 400 & 20 & 115 & 304 & 1900 & 8100 \\
\hline
\end{tabular}

\section{EXPERIMENTAL RESULTS}

\subsection{Load Versus Displacement}

Load - displacement relations for all specimens are shown in Figures 4, 5 and 6. Test results have been separated by the steel tube thickness and bond effects.

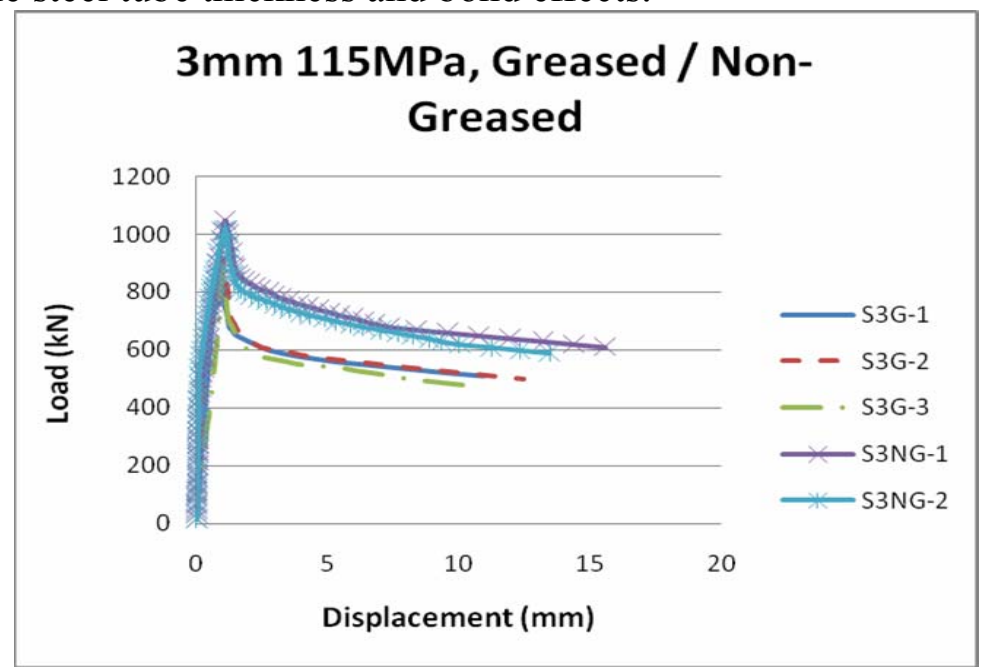

Figure 4. Load-displacement Relation for $3 \mathrm{~mm}$ Steel Tube Thickness 


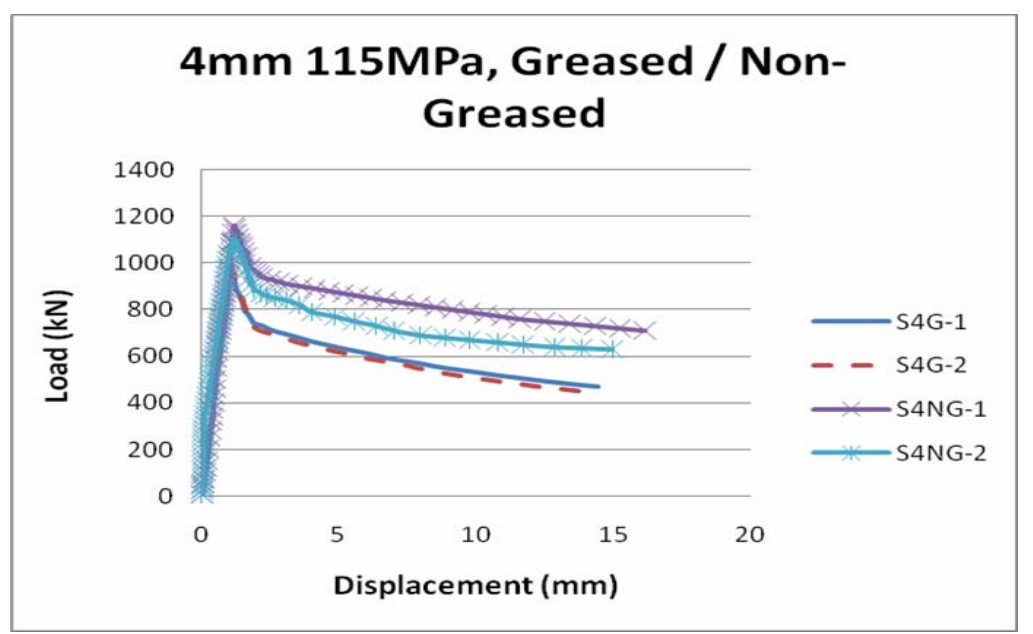

Figure 5. Load-displacement Relation for 4mm Steel Tube Thickness

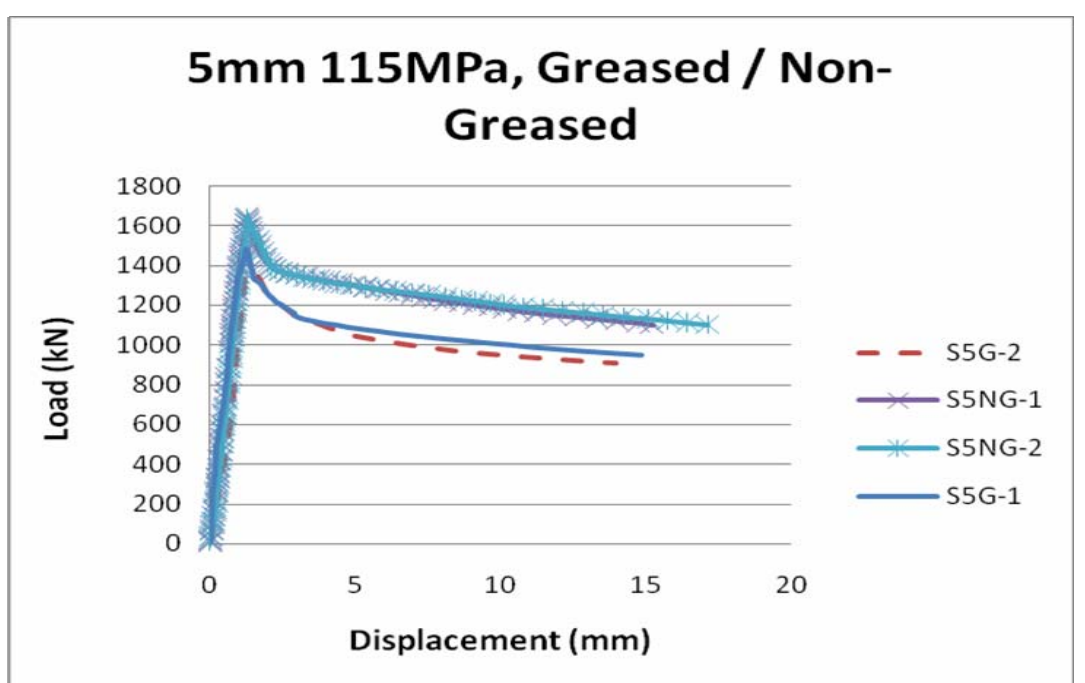

Figure 6. Load-displacement Relation for 5mm Steel Tube Thickness

The load- displacement curves show the axial load capacity and ductility of the SFRC filled steel tube columns. In comparing the load-axial deformation curves for greased and non-greased SFRC filled steel tube columns, the specimens with thicker steel tube wall (smaller $\mathrm{D} / \mathrm{t}$ ratio) show more axial load capacity and ductility. Figures 4, 5 and 6 show the post-yield behavior of each specimen with different steel tube thickness or $\mathrm{D} / \mathrm{t}$ ratio. All specimens exhibit strain-softening characteristic after the specimen reached elastic axial capacity. The difference of the average axial load capacity with respect to steel tube thickness of the greased and non-greased specimens is shown in Table 3.

Table 3. The difference of the average axial load capacity for the greased and non-greased specimens

\begin{tabular}{|c|c|c|c|}
\hline & $\begin{array}{c}\text { The greased } \\
\text { specimens }\end{array}$ & $\begin{array}{c}\text { The non-greased } \\
\text { specimens }\end{array}$ & $\begin{array}{c}\text { The difference of } \\
\text { the average axial } \\
\text { load capacity }\end{array}$ \\
\hline $3 \mathrm{~mm}$ steel tube thickness & $893 \mathrm{kN}$ & $1033 \mathrm{kN}$ & $14 \%$ \\
\hline $4 \mathrm{~mm}$ steel tube thickness & $985 \mathrm{kN}$ & $1130 \mathrm{kN}$ & $13 \%$ \\
\hline $5 \mathrm{~mm}$ steel tube thickness & $1477 \mathrm{kN}$ & $1639 \mathrm{kN}$ & $10 \%$ \\
\hline
\end{tabular}

The local buckling of the steel tubes generally happens on every face of the steel tube. The typical specimen failure modes of the columns are shown in Figure 7. 


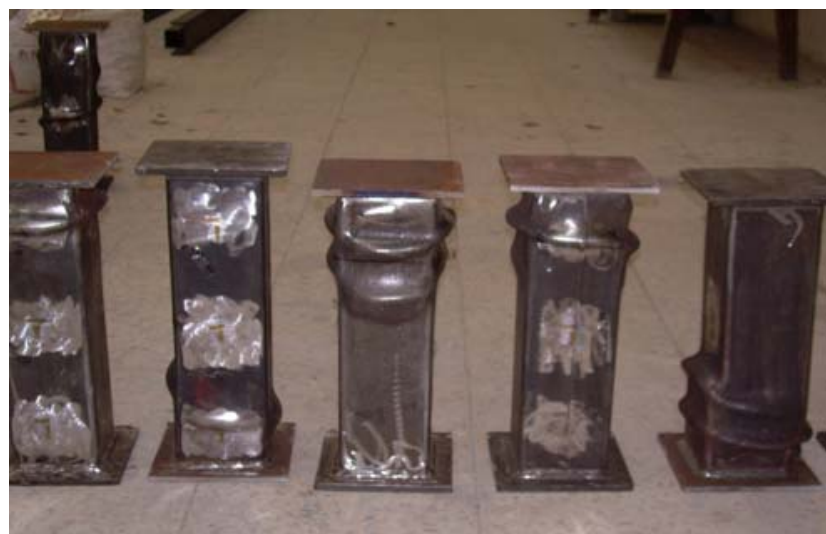

Figure 7. Typical Specimen Failure Modes

\subsection{Ductility Index and Strength Enhancement Index}

Han et al. [9] define some parameters to explain better the strength enhancement and the ductility of the column specimens. These are the strength enhancement index, the ductility index and the

constraining factor. The $\xi$ is the constraining factor defined by Eq. 1, the DI is the ductility index

defined by Eq. 2 and the SI is the strength enhancement index given by Eq. 3 .

$$
\xi=\frac{A_{s} f_{y}}{A_{c} f_{c k}}
$$

$D I=\frac{\delta_{85 \%}}{\delta_{u}}$

$S I=\frac{N_{u, \text { Filled }}}{A_{s} f_{y}+A_{c} f_{c k}}$

Here, $\mathrm{N}_{\mathrm{u} \text {,filled }}$ is the ultimate load reached in the tests, $\delta_{\mathrm{u}}$ is the axial shortening at the ultimate load, $\delta_{85 \%}$ is the axial shortening when the load falls to $85 \%$ of the ultimate load, $A_{s}$ is the steel cross-sectional area, $A_{c}$ is the concrete cross-sectional area, $f_{y}$ and $f_{c k}$ are the yielding stress of the steel tube and the compressive strength of the concrete, respectively. The strength enhancement index (SI) and the ductility index (DI) is shown against the tube diameter to the steel tube wall thickness ratio $(\mathrm{D} / \mathrm{t})$ for the square specimens in Table 4. As seen in Table 4, the relationship between the strength enhancement index (SI) and the constraining factor $(\xi)$ or the ductility index (DI) and the constraining factor $(\xi)$ is linear. This proves that the specimens with thicker steel tube wall exhibit greater ductility and the strength enhancement due to stronger confinement. 
Table 4. The Parameters for the Greased and the Non-greased Specimens

\begin{tabular}{|l|c|c|c|}
\hline & $\xi$ & $D I$ & $S I$ \\
\hline S3G-1 & 0.35 & 1.28 & 0.62 \\
\hline S3G-2 & 0.35 & 1.32 & 0.67 \\
\hline S3G-3 & 0.35 & 1.3 & 0.66 \\
\hline S3NG-1 & 0.35 & 1.41 & 0.77 \\
\hline S3NG-2 & 0.35 & 1.38 & 0.74 \\
\hline S4G-1 & 0.48 & 1.51 & 0.69 \\
\hline S4G-2 & 0.48 & 1.49 & 0.68 \\
\hline S4NG-1 & 0.48 & 1.61 & 0.8 \\
\hline S4NG-2 & 0.48 & 1.58 & 0.76 \\
\hline S5G-1 & 0.62 & 1.71 & 0.98 \\
\hline S5G-2 & 0.62 & 1.69 & 0.97 \\
\hline S5NG-1 & 0.62 & 1.74 & 1.09 \\
\hline S5NG-2 & 0.62 & 1.78 & 1.08 \\
\hline
\end{tabular}

\section{COMPARISON OF THE TEST RESULTS WITH DESIGN CODES}

\subsection{Eurocode 4}

Eurocode 4 (EC4) [16] for square concrete filled steel tubes, the design loads are calculated as the summation of the individual ultimate axial capacities of the steel tube and concrete as given by Eq. 4.

$\mathrm{N}_{\mathrm{u}}=A_{\mathrm{s}} \mathrm{f}_{\mathrm{y}}+A_{\mathrm{c}} \mathrm{f}_{\mathrm{ck}}$

Where, the $f_{c k}$ is the average cylinder compressive strength of concrete, $f_{y}$ is the yield strength of steel tube, $A_{s}$ is the cross-sectional area of steel tube and, $A_{s}$ is the cross-sectional area of core concrete, respectively.

When we compare the ultimate axial loads of test result with the EC4 it can be seen that EC4 is safe for the specimens with $5 \mathrm{~mm}$ steel tube thickness. The largest difference between test and EC4 for the greased and the non-greased specimens is $2 \%$ and $8 \%$. The average $\mathrm{N}_{\text {test }} / \mathrm{N}_{\mathrm{EC} 4}$ for the greased columns is 0.98 and for non-greased columns is 1.09 . The EC4 overestimate the axial load capacity for the specimens with $4 \mathrm{~mm}$ and $3 \mathrm{~mm}$ steel tube thickness. The largest difference between test and EC4 for the greased and non-greased specimens with $4 \mathrm{~mm}$ and $3 \mathrm{~mm}$ steel tube thickness is $32 \%, 24 \%$ and $38 \%$ and $26 \%$, respectively. The average $\mathrm{N}_{\text {test }} / \mathrm{N}_{\mathrm{EC} 4}$ of the greased and non-greased specimens with $4 \mathrm{~mm}$ steel tube thickness is 0.69 and 0.79 , respectively. The average $\mathrm{N}_{\text {test }} / \mathrm{N}_{\mathrm{EC} 4}$ of the greased and non-greased specimens with $3 \mathrm{~mm}$ steel tube thickness is 0.66 and 0.76 , respectively.

\subsection{ACI and Australian Standard}

The American Concrete Institute (ACI) [17] and Australian Standard (AS) [18, 19] use the same formula for calculating the ultimate axial load capacity of square concrete filled tube stub columns. The axial load capacity of the square concrete filled tube columns according to ACI and AS is given in the Eq. 5. 
$\mathrm{N}_{\mathrm{c}, \mathrm{ACI}, \mathrm{AS}}=0.85 \mathrm{~A}_{\mathrm{c}} \mathrm{f}_{\mathrm{ck}}+\mathrm{A}_{\mathrm{s}} \mathrm{f}_{\mathrm{y}}$

The ACI and Australian Standards provide a good prediction of the specimens with thicker (smaller $\mathrm{D} / \mathrm{t}$ ratio) steel tube wall. The average $\mathrm{N}_{\text {test }} / \mathrm{N}_{\mathrm{ACl}, \mathrm{AS}}$ of the greased and non-greased specimens with $5 \mathrm{~mm}$ steel tube wall is 1.08 and 1.2, respectively. The largest difference between test and ACI or Australian Standard for the greased and non-greased specimens is $8 \%$ and $17 \%$, respectively.

For the greased and non-greased specimens with $3 \mathrm{~mm}$ and $4 \mathrm{~mm}$ steel tube thickness, the largest difference between test and ACI or Australian Standard is 30\%, $17 \%$ and $24 \%$ and $15 \%$, respectively. For the specimens with $3 \mathrm{~mm}$ steel tube thickness the average $\mathrm{N}_{\text {test }} / \mathrm{N}_{\mathrm{ACI}, \mathrm{AS}}$ of the greased and the non-greased columns is 0.74 and 0.85 , respectively. The average $\mathrm{N}_{\text {test }} / \mathrm{N}_{\text {ACI,AS }}$ of the greased and non-greased specimens with $4 \mathrm{~mm}$ steel tube thickness is 0.77 and 0.88 , respectively.

\subsection{AISC-LRFD 1999}

American Institute of Steel Construction (AISC) [20] specifications is limited to columns with concrete cylinder strength and steel yield stress not more than 55 and $380 \mathrm{MPa}$, respectively. The axial load capacity of the concrete filled steel tube columns according to AISC is shown in Eqs. 6 to 9 .

$$
\begin{aligned}
& \mathrm{N}_{\mathrm{c}}=A_{s} f_{c r} \\
& \boldsymbol{f}_{c r}=\left(0.658^{\lambda_{c}^{2}}\right) \boldsymbol{f}_{m y} \\
& \lambda_{c}=\left(\frac{L}{r_{s} \pi}\right) \sqrt{\frac{f_{m y}}{E_{s}+0.4 E_{c} \frac{A_{c}}{A_{s}}}} \\
& f_{m y}=f_{y}+0.85 f_{c k} \frac{A_{c}}{A_{s}}
\end{aligned}
$$

Here, $\mathrm{E}_{\mathrm{c}}$, modulus of elasticity of concrete; $\mathrm{E}_{\mathrm{s}}$, modulus of elasticity of steel tube; L, length of column and $r_{s}$ is radius of gyration of steel tube.

AISC provides a good prediction the specimens with thinner steel tube wall compared to thinner ones. For the greased specimens with $3 \mathrm{~mm}, 4 \mathrm{~mm}$ and $5 \mathrm{~mm}$ steel tube thickness, the largest difference between test and AISC is $18 \%, 12 \%$ and $20 \%$, respectively. For the non-greased specimens with $3 \mathrm{~mm}, 4 \mathrm{~mm}$ and $5 \mathrm{~mm}$ steel tube thickness is $3 \%, 4 \%$ and $28 \%$, respectively. The average $\mathrm{N}_{\text {test }} / \mathrm{N}_{\text {AISC }}$ of the greased and non-greased specimens with $3 \mathrm{~mm}, 4 \mathrm{~mm}$ and $5 \mathrm{~mm}$ steel tube thickness is 0.86 and $0.89,1.25$ and $0.99,1.02$ and 1.38 , respectively. The experimental results compared to the design codes are shown in Table 5. 
Table 5. Comparisons of failure loads between test results and design codes

\begin{tabular}{|c|c|c|c|c|c|c|c|}
\hline \multirow[t]{2}{*}{ No } & \multirow[b]{2}{*}{$\begin{array}{l}\mathrm{N}_{\mathrm{ue}} \\
(\mathrm{kN})\end{array}$} & \multicolumn{2}{|l|}{ EC4 } & \multicolumn{2}{|c|}{ ACI,AS } & \multicolumn{2}{|c|}{ AISC } \\
\hline & & $\begin{array}{l}\mathrm{N}_{\mathrm{c}} \\
(\mathrm{kN})\end{array}$ & $\begin{array}{l}\mathrm{N}_{\mathrm{ue}} / \mathrm{N}_{\mathrm{c}} \\
(\mathrm{kN})\end{array}$ & $\begin{array}{l}\mathrm{N}_{\mathrm{c}} \\
(\mathrm{kN})\end{array}$ & $\begin{array}{l}\mathrm{N}_{\mathrm{ue}} / \mathrm{N}_{\mathrm{c}} \\
(\mathrm{kN})\end{array}$ & $\begin{array}{l}\mathrm{N}_{\mathrm{c}} \\
(\mathrm{kN})\end{array}$ & $\begin{array}{l}\mathrm{N}_{\mathrm{ue}} / \mathrm{N}_{\mathrm{c}} \\
(\mathrm{kN})\end{array}$ \\
\hline S3G-1 & 856 & 1370 & 0.62 & 1218 & 0.70 & 1047 & 0.82 \\
\hline S3G-2 & 920 & 1370 & 0.67 & 1218 & 0.76 & 1047 & 0.88 \\
\hline S3G-3 & 902 & 1370 & 0.66 & 1218 & 0.74 & 1047 & 0.86 \\
\hline S3NG-1 & 1049 & 1370 & 0.77 & 1218 & 0.86 & 1047 & 1.00 \\
\hline S3NG-2 & 1017 & 1370 & 0.74 & 1218 & 0.83 & 1047 & 0.97 \\
\hline S4G-1 & 990 & 1440 & 0.69 & 1294 & 0.77 & 1114 & 0.89 \\
\hline S4G-2 & 980 & 1440 & 0.68 & 1294 & 0.76 & 1114 & 0.88 \\
\hline S4NG-1 & 1160 & 1440 & 0.81 & 1294 & 0.90 & 1114 & 1.04 \\
\hline S4NG-2 & 1100 & 1440 & 0.76 & 1294 & 0.85 & 1114 & 0.99 \\
\hline S5G-1 & 1481 & 1509 & 0.98 & 1369 & 1.08 & 1187 & 1.25 \\
\hline S5G-2 & 1474 & 1509 & 0.98 & 1369 & 1.08 & 1187 & 1.24 \\
\hline S5NG-1 & 1642 & 1509 & 1.09 & 1369 & 1.20 & 1187 & 1.38 \\
\hline S5NG-2 & 1636 & 1509 & 1.08 & 1369 & 1.20 & 1187 & 1.38 \\
\hline St. Dev. & & & 0.16 & & 0.17 & & 0.19 \\
\hline
\end{tabular}

\section{CONCLUSIONS}

The main conclusion that we observed from current study as highlighted below.

The Poisson ratio is slightly less and the amount of shrinkage is much higher of the high strength concrete than the medium or low strength concrete. Because of these reasons, the confining effect of the steel tube to the concrete core is not seen much for high strength concrete compared to the low or medium strength concrete.

Therefore, the reduction on the axial load capacity of the column due to the loss of bonding is not negligible for the high strength concrete such as SFRC. In comparing the load-displacement curves for the greased and the non-greased specimens with same steel tube thickness (Figures 4, 5, 6), it is shown that there is a difference on the axial load capacity. However, the bond stress capacity is much higher in the columns with thinner steel tube wall than the thicker (smaller D/t ratio) ones. The difference of the axial load capacity between greased and non-greased specimens with steel tube thickness $3 \mathrm{~mm}, 4 \mathrm{~mm}$ and $5 \mathrm{~mm}$ is $14 \%, 13 \%$ and $10 \%$, respectively.

The increase in the axial load capacity due to the confining effect by the steel tube for the high strength concrete filled tube columns is much less than the medium or low strength concrete ones. Therefore, there is no significant increase in the axial load capacity for the greased and non-greased specimens. In addition to this, the increase in the axial load capacity for the specimens with thinner steel tube thickness is much less than the thicker ones as confining effect is not seen much due to the a great number of local buckling of the thinner steel tube ones.

The SFRC filled steel tube columns with thicker steel tube wall has lower slope of descending branch and show more post-ductile behavior than that of thinner ones. The ductility index (DI) and the strength enhancement index (SI) become higher as the thickness of the steel tube wall increases. 
All design codes overestimate the axial load capacity for the greased and the non-greased specimens with thinner steel tube thickness $(\mathrm{D} / \mathrm{t}$ is 33.3$)$ due to there is little confinement arising from the local buckling of the steel tube. These design codes should use a reduction coefficient in calculating the axial load capacity for the SFRC filled steel tube columns with thinner steel tube thickness to take into account the weak confinement effects.

The specimens with thicker steel tube thickness ( $\mathrm{D} / \mathrm{t}$ is 20$)$ show more axial load capacity due to the effective confinement by the steel tube to the concrete core. These all design codes are conservative in calculating the axial load capacity of the SFRC filled steel tube columns. It can be used a strength enhancement coefficient by these design codes to take into account the confinement effect.

The largest difference between test results and design codes is $38 \%, 30 \%$ and $28 \%$ for the EC4, $\mathrm{ACI}$ and AS and AISC, respectively.

\section{REFERENCES}

[1] Furlong, R.W., "Strength of Steel-encased Concrete Beam-columns", J. Struct. Div, 1967, Vol. 93, pp. 113-24.

[2] Schneider, S.P., “Axially Loaded Concrete-filled Steel Tubes”, Structural Engineering, 1998, Vol. 124, pp. 1125-38.

[3] Roeder, C.W., Cameron, B. and Brown, C.B., "Composite Action in Concrete Filled Tubes", Journal of Structural Engineering, 1998, Vol. 125, pp. 477-84.

[4] Giakoumelis, G. and Lam, D., "Axial Capacity of Circular Concrete-filled Tube Columns”, Journal of Constructional Steel Research, 2004, Vol. 60, pp. 1049-68.

[5] Morishita, Y., Tomii, M. and Yoshimura, K., "Experimental Studies on Bond Strength in Concrete Filled on Square and Octagonal Steel Tubular Columns Subjected to Axial Loads", Trans Japan Concrete Institute, Tokyo, 1979, pp.359-66.

[6] Virdi, K.S. and Dowling, P.J., "Bond Strength in Concrete Filled Circular Steel Tubes", CESLIC Rep. CC11, Eng. Strctr. Lab, Civil Engineering Dept, Imperial College, London, 1975.

[7] Campiogne, G., Mindess, S., Scibilia, N. and Zingone, G., "Strength of Hollow Circular Steel Sections Filled with Fiber-reinforced Concrete", Can. Journal of Civil Engineering, 2000, Vol. 27, pp. 364-372.

[8] Uy, B., "Strength of Short Concrete Filled High Strength Steel Box Columns", Journal of Constructional Steel Research, 2001, Vol. 57, pp. 113-34.

[9] Han, L.H., "Tests on Stub Columns of Concrete-filled RHS Sections", Journal of Constructional Steel Research, 2002, Vol. 58, pp. 353-72.

[10] Hu, H.T., Huang, C.H., Wu, M.H. and Wu, Y.M., "Nonlinear Analysis of Axially Loaded Concrete-filled Tube Columns with Confinement Effect", Journal of Structural Engineering, ASCE, 2003, Vol. 129, pp. 1322-1329.

[11] Young, B. and Ellobody, E., "Experimental Investigation of Concrete-filled Cold-formed High Strength Stainless Steel Tube Columns", Journal of Constructional Steel Research, 2006, Vol. 62, pp. 484-92.

[12] Teng, J.G., Yu, T., Wong, Y.L. and Dong, S.L., "Hybrid FRP-concrete-steel Tubular Columns: Concept and Behavior", Construction and Building Materials, 2007, Vol. 21, pp. 846-854. 
[13] Zhong, T., Han, L.H. and Wang, D.Y., "Strength and Ductility of Stiffened Thin-walled Hollow Steel Structural Stub Columns Filled with Concrete", Thin Walled Structures, 2008, Vol. 46, pp. 1113-28.

[14] Liang, Q.Q. and Fragomeni, S., "Nonlinear Analysis of Circular Concrete-filled Steel Tubular Short Columns under Eccentric Loading”, Journal of Constructional Steel Research, 2010, Vol. 66, No. 2, pp. 159-169.

[15] Zhao, H.L. and Zhao, Y.G., "Suggested Empirical Models for the Axial Capacity of Circular CFT Stub Columns", Journal of Constructional Steel Research, 2010, Vol. 66, pp. 850-62.

[16] Eurocode4, "Design of Composite Steel and Concrete Structures", Brussels, Belgium, 1994.

[17] ACI 318-05, "Building Code Requirements for Structural Concrete and Commentary", Farmington Hills, American Concrete Institute, 2005.

[18] Australian Standards, "Steel Structures", AS4100-1998, Sydney (Australia): Standards Association of Australia, 1998.

[19] Australian Standards, “Concrete Structures”, AS3600-2001.Sydney (Australia): Standards Association of Australia, 2001.

[20] AISC, "Load and Resistance Factor Design (LRFD) Specification for Structural Steel Buildings", Chicago, American Institute of Steel Construction, 1999. 